\title{
Central serous retinopathy as presentation of an adrenal adenoma
}

\author{
Brijesh Takkar, ${ }^{1,2}$ Shreyas Temkar, ${ }^{1}$ Nripen Gaur, ${ }^{1}$ Pradeep Venkatesh ${ }^{1}$
}

'Department of Ophthalmology, Dr Rajendra Prasad Centre for Ophthalmic Sciences, All India Institute of Medical Sciences, New Delhi, Delhi, India ${ }^{2}$ Department of Ophthalmology, All India Institute of Medical Sciences, Bhopal, MP, India

Correspondence to Dr Brijesh Takkar, britak.aiims@gmail.com

Accepted 3 December 2018
Check for updates

(C) BMJ Publishing Group Limited 2018. No commercial re-use. See rights and permissions. Published by BMJ.

To cite: Takkar B, Temkar S, Gaur N, et al. BMJ Case Rep 2018;11:e227315. doi:10.1136/bcr-2018227315

\section{DESCRIPTION}

A 42-year-old diabetic and hypertensive woman had presented with acute vision loss in the right eye (RE) in 2012. She was noted to have Cushingoid features-obesity, facial puffiness and pruritic blue coloured striae. Visual acuity at presentation was 6/36 in the RE and 6/6 in the left eye (LE). She was diagnosed to have exudative retinal detachment (RD) in the RE and pigment epithelial detachment (PED) with peripheral subretinal fluid in the LE. Fundus fluorescein angiography (FFA) had revealed multiple areas of dye leakage, suggesting multifocal central serous retinopathy (CSR) in both eyes (BE). Endocrinology workup revealed no change in serum cortisol levels following low-dose dexamethasone suppression test along with undetectable serum adrenocorticotropic hormone (ACTH) levels. She was hence diagnosed to have ACTH-independent Cushing syndrome. Further workup revealed right adrenal adenoma and normal pituitary gland on radioimaging. During this period, the CSR and RD resolved, and she recovered vision in the RE. She was advised adrenalectomy but defaulted.

Two years later, she developed shortness of breath due to dilated cardiomyopathy and easy bruisability, proximal muscle weakness with an acute weight gain of $4 \mathrm{~kg}$ over the past 2 months. An uneventful laparoscopic adrenalectomy was performed. She

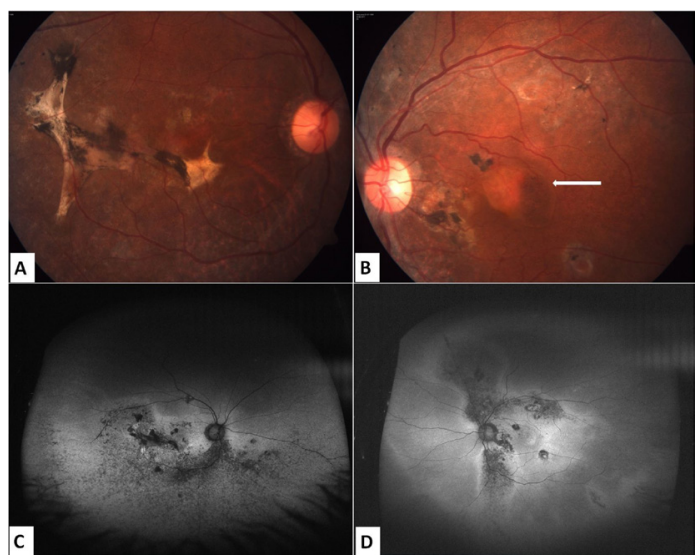

Figure 1 Fundus photographs of the patient. (A) Pigment loss can be seen in the right eye. A dense subretinal fibrotic scar is noticeable, extending from the inferior subfoveal region to the temporal macula. (B) Left eye image showing pigment mottling in the posterior pole. Large PED can be seen (arrow). (C and D) Autofluorescence images showing hypofluorescence corresponding to distribution of subretinal fluid and minimal hyperfluorescence corresponding to PED of the left eye. PED, pigment epithelium detachment. was being maintained on low-dose oral steroids due to very low serum cortisol levels when she developed minimal blurring of vision in the LE in 2017. BCVA was 6/6 in the RE and 6/9 in the LE. Anterior segment and intraocular pressure of $\mathrm{BE}$ were normal, but for minimal posterior subcapsular cataract. Fundus examination revealed loss of pigment in the macular area and subretinal fibrotic bands extending from the subfoveal region to temporal macula in the RE (figure 1), with signs of altered pigmentation in the peripheral retina. Evaluation of the LE revealed a fresh subfoveal PEDs, apart from pigment mottling in the macula (figure 1). Ultra-wide field autofluorescence imaging revealed areas of hypoautofluorescence corresponding to the distribution of previous subretinal fluid in $\mathrm{BE}$ (figure 1), and minimal hyperautofluorescence in the area corresponding to PED in the LE. Optical coherence tomography ruled out subretinal fluid in $\mathrm{BE}$ (figure 2). FFA did not reveal any area of dye

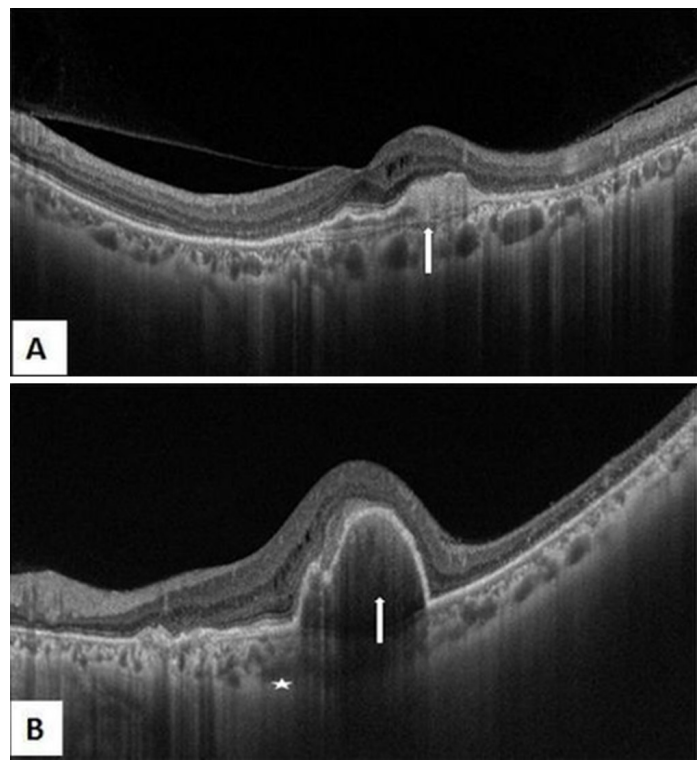

Figure 2 Swept source optical coherence tomography images. (A) Right eye image showing vitreomacular adhesion with shallow foveal contour and disorganised foveal outer retinal layers. Elevation of the retinal pigment epithelium (arrow) can be seen due to scarring along with cystic spaces middle macular layers. Prominent large dilated choroidal vessels (arrowheads) with partially obscured choriocapillaris are also evident. (B) Left eye image shows absent foveal contour, middle retinal cystic spaces with large pigment epithelial detachments (arrow). The choroid in the subfoveal region is obscured due to optical shadowing though visible areas show some large dilated choroidal vessels (star). 
leakage. The patient was diagnosed to have resolved CSR with PED in the LE and advised observation. The condition remained stable till a further observation period of 6 months.

The role of ACTH in causing increased choroidal thickness has been studied recently in patients of endogenous Cushing syndrome. ${ }^{12}$ Cushing syndrome due to adrenal adenoma or benign adrenal hyperplasia, however, is independent of ACTH. In the previous reports regarding CSR in patients with ACTH-independent Cushing syndrome secondary to adrenocortical adenoma, the findings were typically bilateral multifocal posterior pigment epitheliopathy, a form of chronic CSR. The disease showed remarkable response following surgical management of the adenoma. ${ }^{12}$ Increased fragility of choriocapillaris

\section{Learning points}

- Central serous retinopathy (CSR) can rarely be the initial presentation of adrenocorticotropic hormone-independent endogenous Cushing syndrome due to adrenal adenoma.

- Use of maintenance steroids in such cases of CSR following adrenalectomy is a matter of careful deliberation. together with local ischaemia due to the reduction in fibrinolysis as a response to free plasma glucocorticoids may be the aetiology of CSR. ${ }^{23}$ Our patient had initially presented with CSR related to an adrenal adenoma, which is a very rare occurrence, and the second occurrence was possibly related to the maintenance steroids.

Contributors BT, ST and PV worked up and diagnosed the patient. BT and PV performed imaging. BT and NG wrote the script. All authors critically revised the text. $\mathrm{PV}$ is the overall guarantor of the paper.

Funding The authors have not declared a specific grant for this research from any funding agency in the public, commercial or not-for-profit sectors.

Competing interests None declared.

Patient consent for publication Obtained.

Provenance and peer review Not commissioned; externally peer reviewed.

\section{REFERENCES}

1 lannetti L, Spinucci G, Pesci FR, et al. Central serous chorioretinopathy as a presenting symptom of endogenous Cushing syndrome: a case report. Eur J Ophthalmol 2011:21:661-4.

2 Pastor-Idoate S, Peña D, Herreras JM. Adrenocortical adenoma and central serous chorioretinopathy: a rare association? Case Rep Ophthalmol 2011;2:327-32.

3 Nicholson BP, Atchison E, Idris AA, et al. Central serous chorioretinopathy and glucocorticoids: an update on evidence for association. Surv Ophthalmol 2018;63:1-8.

Copyright 2018 BMJ Publishing Group. All rights reserved. For permission to reuse any of this content visit https://www.bmj.com/company/products-services/rights-and-licensing/permissions/

BMJ Case Report Fellows may re-use this article for personal use and teaching without any further permission.

Become a Fellow of BMJ Case Reports today and you can:

- Submit as many cases as you like

Enjoy fast sympathetic peer review and rapid publication of accepted articles

- Access all the published articles

- Re-use any of the published material for personal use and teaching without further permission

For information on Institutional Fellowships contact consortiasales@bmjgroup.com

Visit casereports.bmj.com for more articles like this and to become a Fellow 